\title{
A Case Study: History of Polish Computer Applications in Power System Control
}

\section{Jozef B. Lewoc ${ }^{1}$, Antoni Izworski ${ }^{2}$, Slawomir Skowronski ${ }^{3}$, and Antonina Kieleczawa ${ }^{4}$}

${ }^{1}$ BPBiT Leader, Powst. Sl. 193/28, 53-138 Wroclaw, Poland; leader@provider.pl

2 Wroclaw University of Technology, Wyb. Wyspianskiego 27, 50-370 Wroclaw, Poland; antoni.izworski@pwr.wroc.pl

${ }^{3}$ Wroclaw University of Technology, Wyb. Wyspianskiego 27, 50-370 Wroclaw, Poland; slawomir.skowronski@pwr.wroc.pl

${ }^{4}$ Institute of Power System Automation, ul. Wystawowa 1, 51-618 Wroclaw, Poland; tosia@iase.wroc.pl

\begin{abstract}
In spite of the difference in the country development level, especially in computer and automation technology, between Poland and well developed countries, the history of local computer control applications in the Polish power industry is rather interesting. The paper has been prepared by the IFAC Technical Committee SWISS due to significant social political and cultural aspects of power system control and describes the history of the power system projects implemented in the country by the leading power system automation centre.
\end{abstract}

Keywords: Electric power systems, Energy expenditure, Automation, Monitoring, Computer networks

\section{Introduction}

In the pioneering times of computer control applications in the power industry in Poland, i.e. in the seventies, there was a big difference between this case study country and typical well developed countries of the West. In the computer technology, the time lag between the computers available in the case study country and those available in the West was assessed at some $5-10$ years, what can be compared to infinity for this fast growing technological domain. In addition, the case study country was governed by communist system severely impeding normal human life to say nothing of High-Tech activities.

However, Polish implementations of computer automation in the power industry are rather interesting. In particular, this refers to the Institute of Power 
System Automation (IASE) in Wroclaw, the definite Polish leader in power industry computer control applications during the pioneering times.

This paradoxical situation has induced often questions concerning how was it possible to develop useful computer systems with so big time delays in available computers and how was it done.

To answer the questions, a series of three papers have been prepared: two for the 17-th IFAC Congress '08 in Seoul and one for the IFIP Congress in Milano. The present paper describes the history of power industry computer control applications developed by IASE. Another paper [1] describes major technical and political problems that must have been solved by the design and implementation team to develop and implement successfully the computer control systems in the power industry. Still another paper [3] describes major technical solutions applied in the computer control systems.

The three papers have been prepared by the IFAC Technical Committee SWISS (Supplemental Ways for Increasing Social Stability) within the statute activity range of the Committee since the problems addressed therein are strongly connected with the social, political and cultural aspects of technology and the power system control domain is of major technological, scientific and social impacts.

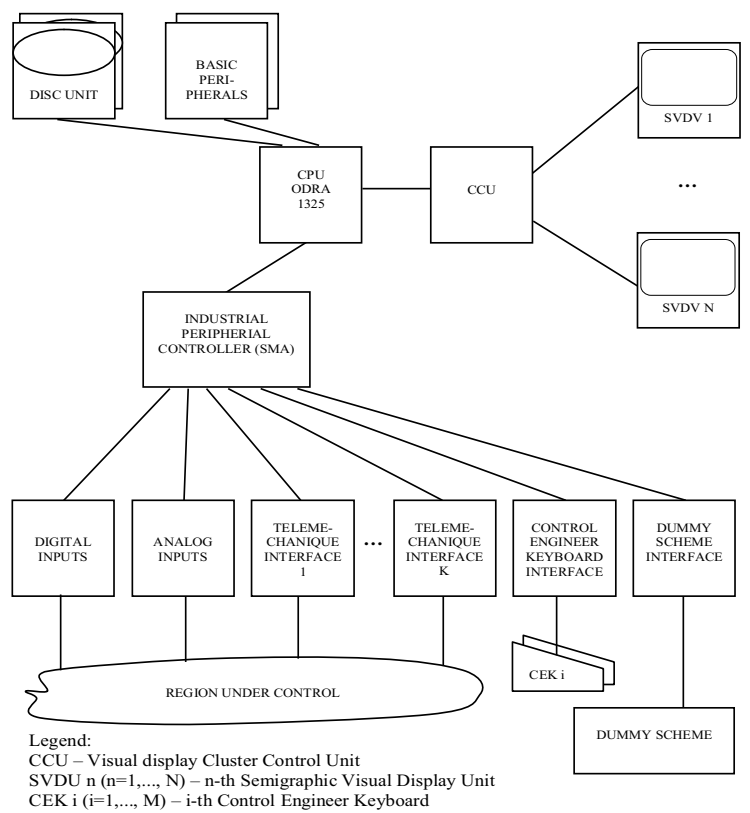

Figure 1 Hardware architecture of SAPI ODM 


\section{SAPI ODM}

The first successful Polish large-scale computer automation system in the power industry and, at the same time, in any Polish industry was the regional power dispatching control system (SAPI ODM) (ref. Figure 1) [3]. The purpose of SOSAPI ODM was to collect information from the region under control, to enable effective monitoring of the information collected and to work out control decisions necessary to operate the power industry region in an adequate fashion, especially in emergency conditions. Some SAPI ODM functions (e.g. water power plant control) were to run in the automatic mode.

Some idea of the complexity of the problems to be solved may be given by the number of the inputs to be processed by SAPI ODM: several thousand analogue inputs and a similar number of digital inputs.

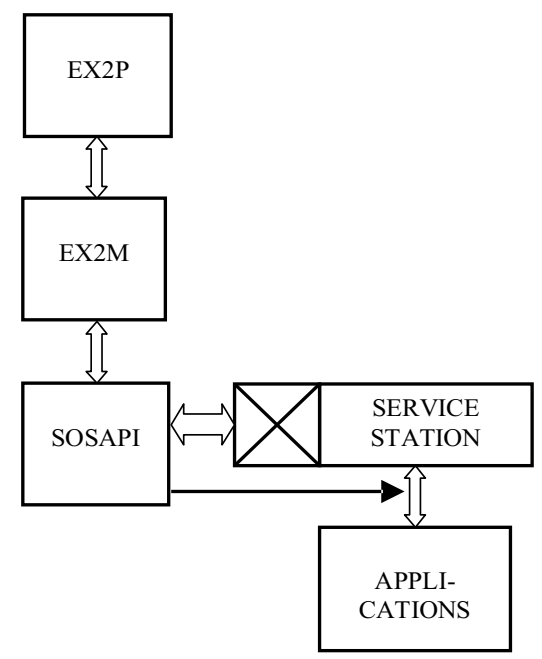

Figure 2a Software architecture of SAPI ODM

It was a prerequisite of the project that SAPI ODM was implemented on a Polish computer. The only available was Odra 1325 (ICL 1902a Compatible) [4]. The original computer (ICL 1902a) was oriented towards numerical data processing and not industrial control applications. Therefore, there was designed and implemented the industrial peripheral system (SMA) and specific peripherals needed for the power system monitoring purposes [4]. To run the hardware architecture of Figure 1, a software system was developed (ref. Figure 2a,), executing the functional diagram presented in Figure $2 \mathrm{~b}$. The SAPI ODM software consisted of the following basic components: 
- EX2M executive, i.e. a general-purpose operating system for numerical data processing,

- EX2P industrial executive, i.e. EX2M + SMA industrial peripheral system drivers,

- SOSAPI, i.e. power system control oriented operating system (a trusted program running under EX2P and including the primary data processing routines, [5], of the most severe time constraints),

- APPLICATIONS, i.e. a set of data processing programs (PUCs (Programs Under Control)).

In spite of severe technical, social and political problems [1] and due to the solutions devised by the design and implementation team [2], the first successful version of SAPI ODM was implemented in the Central Power Industry Region in 1976. The two next versions were implemented in the Western and Eastern Regions; in addition, one big lower level power control centre was automated using the SAPI ODM solutions.

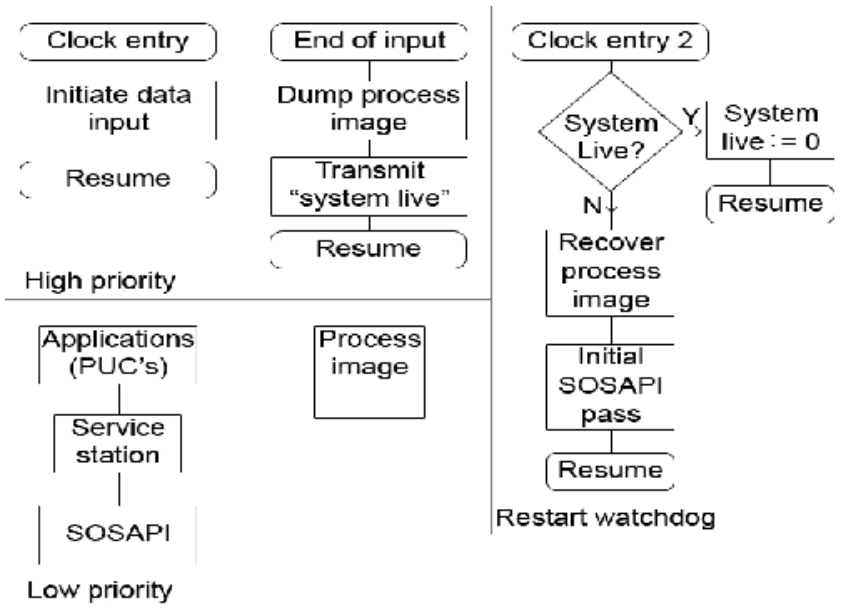

Figure 2b Functional architecture of SAPI ODM

SAPI ODMs controlled more than half energy flowing in the case study country grid for more than 15 years. Considering the problems that had to be solved by the design and implementation team, this was a remarkable technical success. But not only technical. Because of political reasons, nobody tried to evaluate the economic benefits generated by SAPI ODMs. However, it is not too difficult. In the case study country, it was accepted commonly to assess the economical benefits generated by a power control system at the level of a dozen or so percent of the price of the energy under monitoring. Assuming 10\%, the benefits gained due to savings of more than $50 \%$ energy of the case study country during 15 years exceed $\$ 40000000000$. Even if the assumptions concerning the 
economic benefits are too optimistic, the figure is some measure of the economic success of the project SAPI ODM.

\section{PGU Monitor}

Since the results of SAPI ODM design and implementation teams were considered promising and there were major time delays in delivery of the industrial peripheral system SMA, the team was employed in development of a Power Generating Unit Monitor (PGU Monitor). This project was financed from the funds devoted to the nuclear power plant that was to be developed in the case study country (luckily enough, the decision was withdrew several years later). The simplified hardware architecture of PGU Monitor is shown in Figure 3.

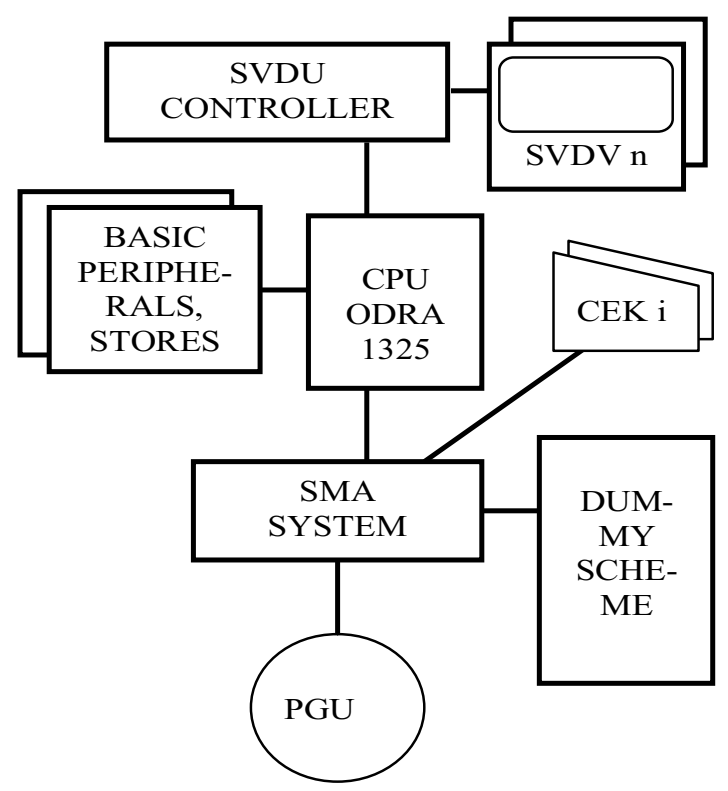

Figure 3 Simplified hardware architecture of PGU MONITOR

In the PGU Monitor, the software of SAPI ODM was used, except of the Application software that was to be written based on that employed in SAPI ODMs, [5]. PGU Monitor was commissioned successfully on a $200 \mathrm{MW}$ power generating unit and during almost a yearly test operation period it enabled to acquire a lot of useful information concerning actual power generating unit monitoring problems. 


\section{Intelligent Cluster Control Unit}

However, when developing SAPI ODM, a very good solution (at least, as for that time) was designed and implemented [1], the importation barriers in the case study country were a severe limitation for the cluster control unit. Therefore, it was decided to develop a home solution for the power industry visualisation systems. The design team decided to make use of a small home minicomputer and home scheme visual display units and to develop the first intelligent peripheral in the case study country.

The hardware structure of the intelligent peripheral (CCU emulator) [6] is shown in Figure 4 a while the functional architecture of the intelligent cluster control unit - in Figure 4b.

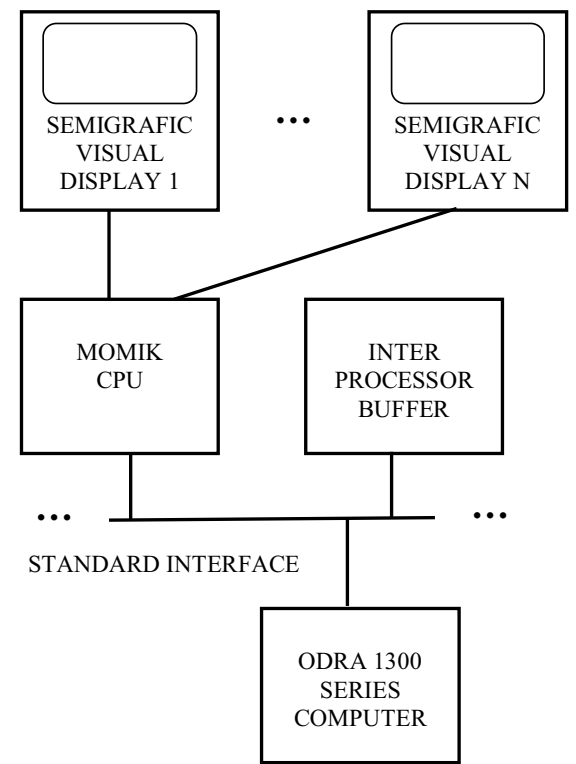

Figure 4a Hardware structure of CCU emulator

The CCU emulator software (Figure 4b) written in the Momik minicomputer assembler language made use of the Momik capabilities at their maximum: For the maximum configuration of 16 VDUs, there were only about 20 spare memory bytes left. This is an evidence for the team's approach consisting in taking the maximum possible use of available hardware. 


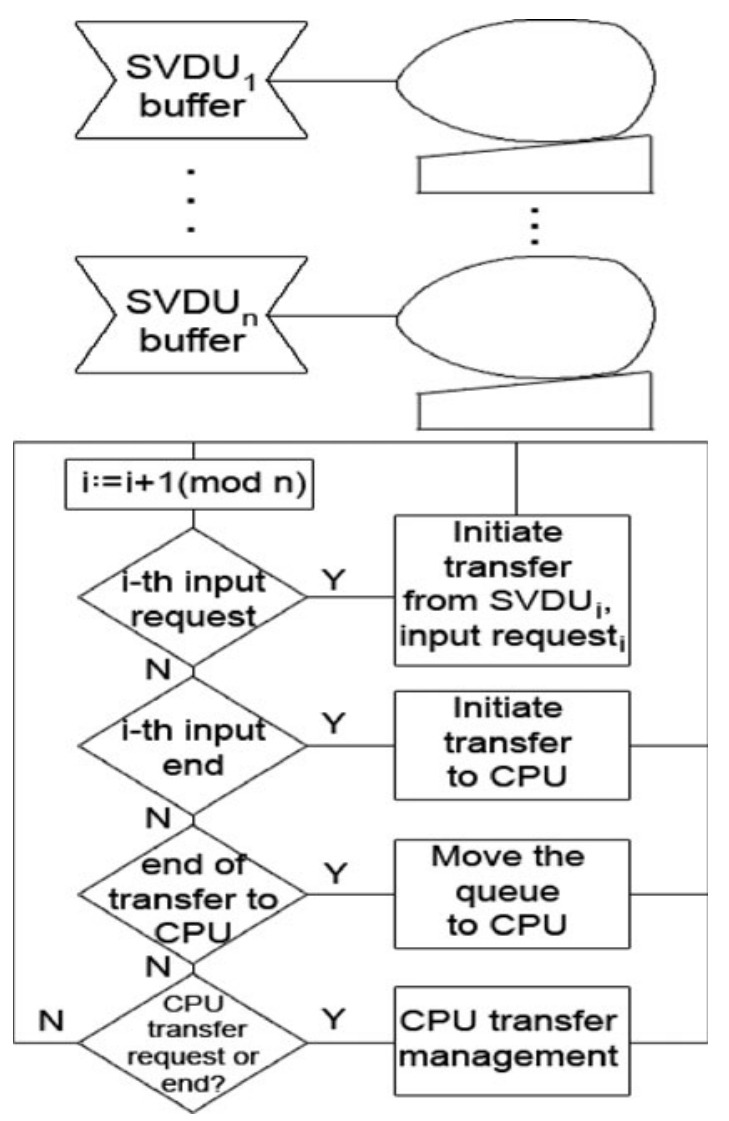

Figure 4b Functional architecture of intelligent power system visual display unit cluster software

The project was successful: the Polish SVDU configurations were successfully applied in several power industrial computer control systems, including the PGU Monitor (Figure Section 3) and the power system simulators (ref. Section 5).

\section{Power Grid Training Simulator}

Because of SAPI ODM, a power grid training simulator was developed intended for training power network control engineers (Simulator). The hardware structure of the simulator is that of a typical SAPI ODM (ref. Figure 1) plus a trainee console and a trainer console. However, the software architecture of SOSAPI had to be upgraded to enable running two types of PUCs: power grid models (at a 
lower priority level) and simulation co-ordinators of a higher pre-emptive priority (ref. Figure 5) [7], [8].

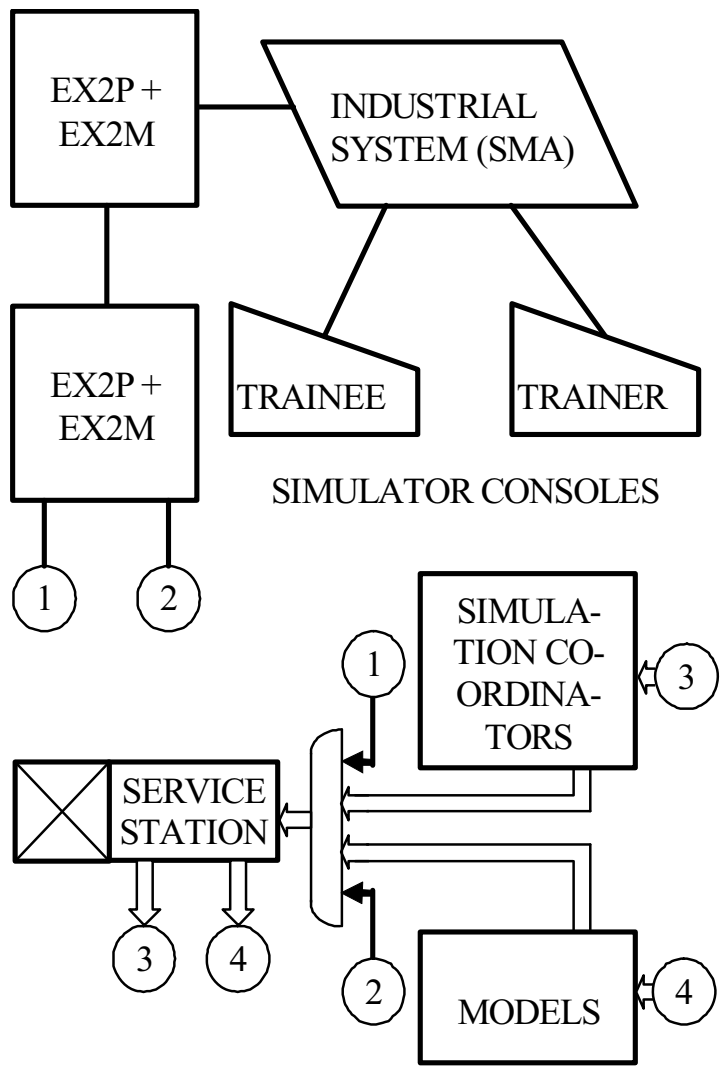

Figure 5 Software architecture of the simulator

\section{Further Versions of SAPI ODM}

\subsection{Microprocessor Based Version}

The success of various SAPI ODM applications and the new technologies being available in the case study country made the design and implementation team to think about other versions of the system. 


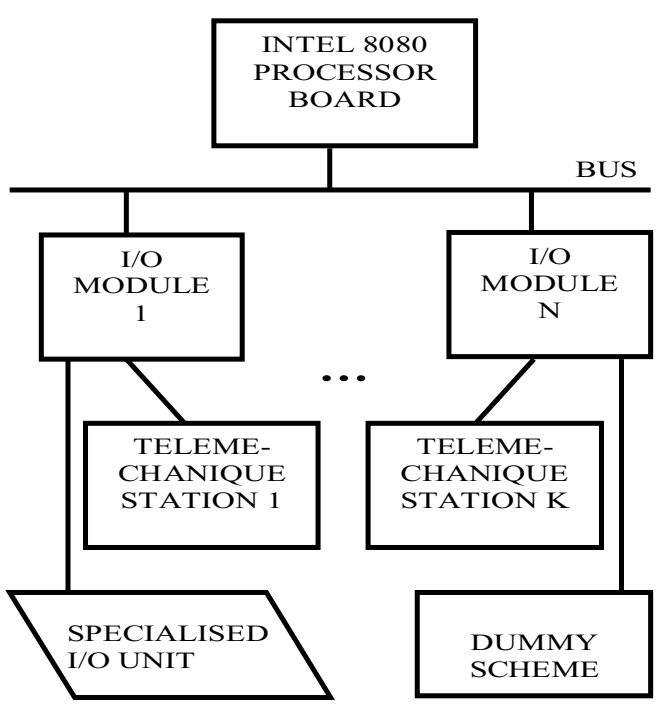

Figure 6 Hardware structure of KWP

For area power system control centres, a microprocessor version was developed reflecting, though in a much smaller scale, the computer system. This version, implemented on the Intel 8080 technology, was called a commutated measurement display KWP and had the hardware structure shown schematically in Figure 6.

KWP was successfully implemented in several lower level power control centres. Though its capabilities were lower than those of computer based SAPI ODMs, it was rather a handy tool requiring no too much room and no special environment [6], [10].

\subsection{IBM PC Version}

In early nineties, the basis SOSAPI version and APPLICATION PUCs were transferred on the IBM PC computer. Due to the complete documentation of software (complete detailed flowcharts were available), this task could be done rather easily and effectively.

There were two successful implementations of the IBM PC version of SAPI ODM, one in a big town electric power utility and the other in a big 400/110 kV switching station [11]. 


\section{Computer Integrated Manufacturing and Management System for Power Plants}

Already in late eighties, series work was undertaken to develop a combined integrated power manufacturing and management system for a big power plant under construction. Similar Computer Integrated Management systems (CIMMs) are severely needed by the users of various industries but, most regretfully, they are not available in the Information and Communication Technology (ICT) market so some work has been done in the domain ([12], [13], [14], [15], [16], being in a large part a continuation of the work mentioned in the present Section of this paper.

When commencing the planning work for this project, it was decided that it would be cheaper to develop a program generator and generate rather then program software for the six power generating units of the power plant under development and to develop the management and manufacturing solution by a single team under one order; therefore, hardware and software facilities should be provided for the CIMMs approach from the very beginning.

The hardware architecture designed for Badel (from Polish (rozproszona) Baza danych dla elektrowni $=($ distributed $)$ database for power plants $)$ is presented in Figure 7.

The hardware architecture includes $\mathrm{N}(\mathrm{N}=6$ for the pilot power plant under construction) power generating unit (PGU) computing facilities $\left\{S C_{n, k(n)}\right\}_{n=1, k(n)=1}^{N, K(n)}$, that are the sequential control systems for the n-th PGU, and $\left\{D A Q_{n, k(n)}\right\}_{n=1, l(n)}^{N, L(n)}$, i.e. the data acquisition computers for the n-th PGU.

In addition, for each power generating unit $\left\{P G U_{n}\right\}_{n=1}^{N}$, there should be developed the control processor $\left\{C P_{n}\right\}_{n=1}^{N}$, the presentation processor $\left\{P P_{n}\right\}_{n=1}^{N}$ and the operator's visualisation system console $\left\{\text { Console }_{n}\right\}_{n=1}^{N}$

The single power generating unit outfit system was known as KSWDB (from Polish Komputerowy System Wspomagania Dyspozytora Bloku = computer power generating unit control engineer's supporting system).

The first phase of Badel (consisting of KSWDB passed successfully laboratory tests in the Institute in the early nineties. Unfortunately, this was a very low economy period in the case country, the demand for power was low and construction of the power plant was intentionally delayed of several years. Due to that, Badel could not be developed further and the design and implementation team had to be disassembled. Nevertheless, the work done by the team (some ready-made programs, flow diagrams and ideas devised when designing and testing KSWDB) has been used in further successful applications of ICT in the power industry control (some of this is mentioned hereinafter). Therefore, the authors considered it purposeful and worthwhile to mention Badel when 
describing the history of the most important ICT applications in the power industry of the case study country.

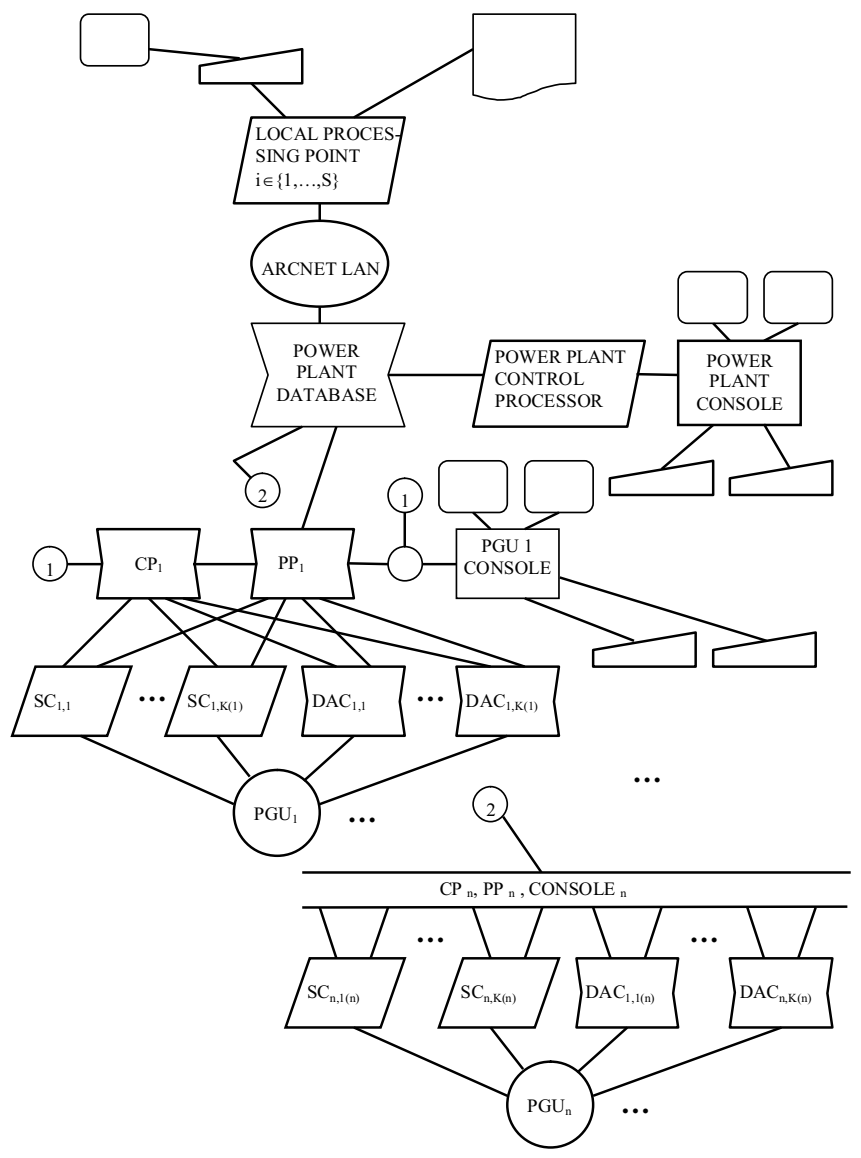

Figure 7 Hardware architecture of Badel

After several years passed, the power plant construction work was resumed and the problem of the ICT solutions for the power appeared again. However, the design and implementation team was not re-assembled and the job was entrusted to a big international corporation, a world leader, at least in theory, in the technology transfer in the domain of ICT for automation. The corporation had not offered the complex CIMM solutions but they also were not apt to re-assemble the Badel design and implementation team or to continue its work. Consequently, the system comparable with KSWDB was, for years, the only outcome of their actions. Thus, the work organisation decisions of the corporation resulted in a lose-and-lose solution: the design and implementation team members did not get 
the job they liked and the corporation did not get satisfactory results of their work. Unfortunately, the "technology transfer" process in the case study country was full of similar paradoxical events ([16], [17], [18]).

\section{Computer System Powerster Supporting Power Generation and Distribution Facility Control}

The history of computer power system monitoring and control in the case study country finishes, in practice, at the Powerster Dispatching System, being a successor of KSWDB (ref. Section 7 Hereinabove) implemented on IBP PC compatibles in early nineties and having been developed and upgraded till now, and implemented successfully in more than a hundred heat and power distribution and generation applications. See Figure 8 .
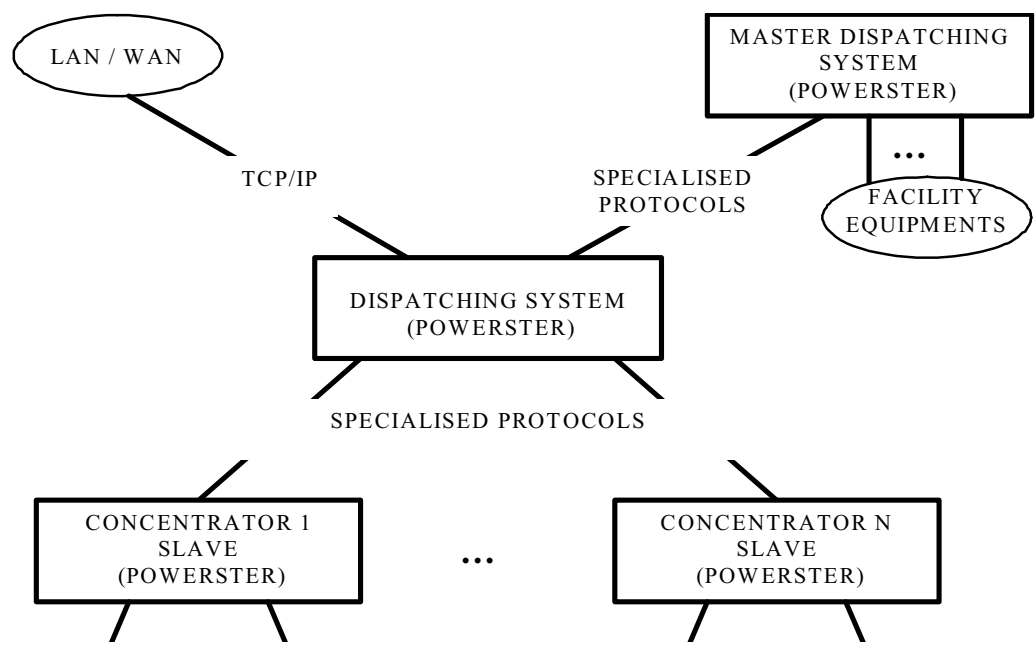

DISPATCHING NETWORK PERIPHERAL PROTOCOLS
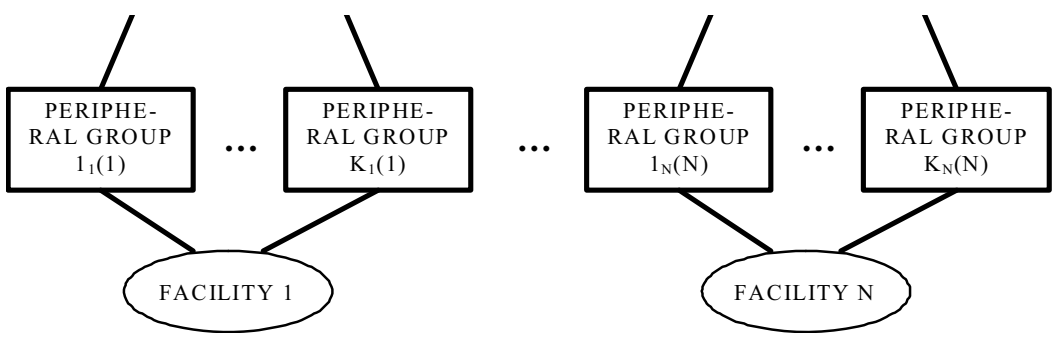

Figure 8 Typical Powerster-based dispatching system network 


\section{Performance Evaluation Work}

Considering the fact that hardware and software tools available to the Team were always obsolete of some 5 to 10 years with respect to those used by designers in well-developed countries, serious approach to the performance problems was a must. The team started from event-driven simulators and, at the end, developed their own approximate throughput evaluation tool depicted in Figure 9 ([21]) with an exemplary closed loop investigated with the tool depicted in Figure 10.

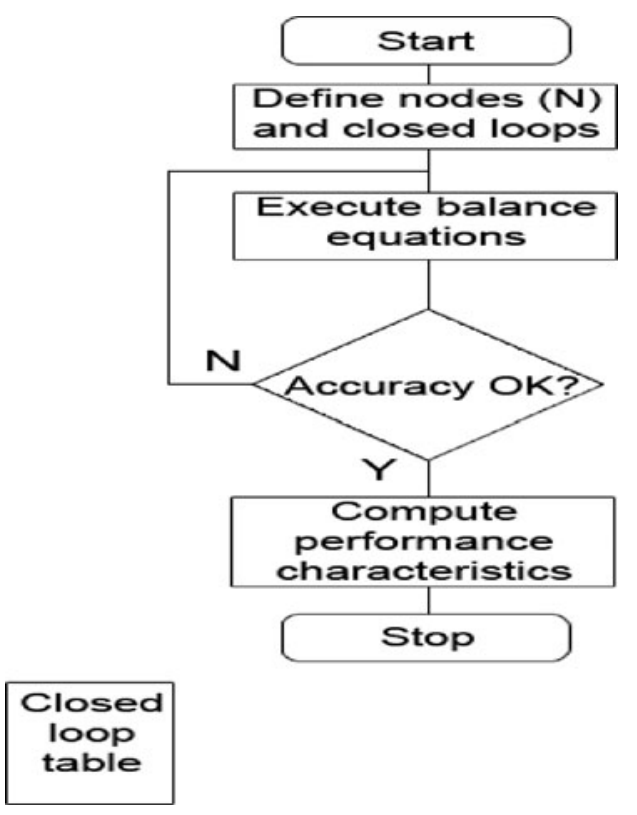

Figure 9 Functional architecture of approximate analytical performance evaluation tool

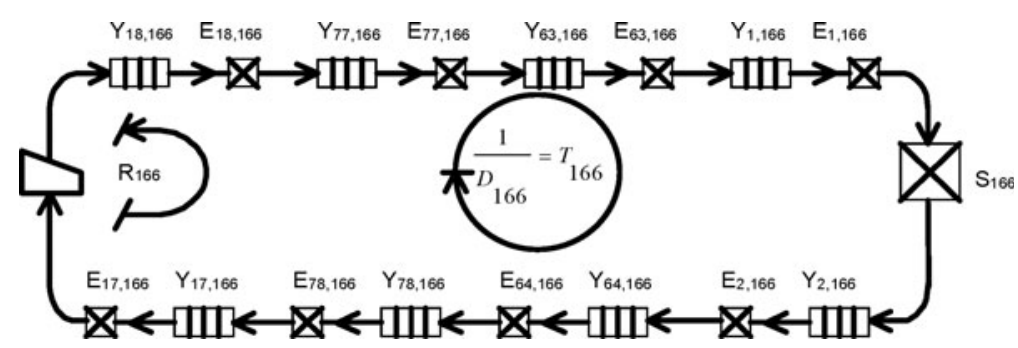

Figure 10 Exemplary closed loop investigated by the approximate throughput evaluation tool 


\section{References}

1. Han M.W., Lewoc J.B., Izworski A., Skowronski S. and Kieleczawa A., Power Industry Computer Control System Design and Implementation Problems: A Case Study of Poland, In the 17-th IFAC Congress, Seoul 2008.

2. Lewoc J.B., Kieleczawa A., Tomczyk A., Ziaja E. Izworski A. and Skowronski S., The Role of IASE In Design and Development of Pioneering ICT Systems for Power Industry In Poland, The 14-th International WOSK Congress, Wroclaw, 2008.

3. Sawicki J., Kowalski A.J. and Lewoc J., Implementation of the Automatic Data - Processing for the Power System Control in Poland, Data - Processing Conference, Nr 5.1.11, Madrid, 1974.

4. Elwro, Electronic Computer Odra 1325, Operating and Maintenance Manual (in Polish), Wroclaw, 1976.

5. Lewoc J. et al., Primary Data Processing Methods Applied in Power Generating Unit Computer Monitoring System, Power System Conference, Prague 1978.

6. Lewoc J.B., A Microcomputer Data Acquisition and Retrieval System for Power Distribution Boards, Microelectronics 1984, Prague 1984.

7. Lewoc J. and Rozent M., An Operating System for Digital Simulator of Power Generating Unit, In: Future Progress of Electrical Engineering, Prague 1975.

8. Lewoc J., Nawojski J. and Worsztynowicz E., Two-program operating system for digital simulators of complex power systems, Prace IASE, vol. 35, 1980 (in Polish).

9. Lewoc J.B., Rozent M. and Weksej E., A Power System Simulator: Participation of People Involved. In: ASBoHS (IFAC), Madison 1992.

10. Lewoc J.B. and Lanowska B., Microcomputer Data Display System for Power Industry Applications. In: MicroP '83, Budapest 1983.

11. Bujko J. and Lysiak E., IASE History. Prace IASE, Vol. 45, Wroclaw 1999 (In Polish).

12. Franasik L. et al, System Media - a Step toward Computer Integrated Manufacturing and Management Systems, Modelling, Measurement and Control (AMSE Press), vol. 22 No. 3, pp. 37-46, 2001.

13. Izworski A. and Lewoc J.B., Robustness Comparison of Enterprise Energy Distribution Systems of Various Topologies. In: Robust System Design (IFAC), Milan, 2003.

14. Izworski A., Lewoc J.B. and Skowronski S., Development of Computer Integrated Manufacturing and Management Systems. In: Information Control Problems in Manufacturing (IFAC), Saint Etienne, 2006.

15. Lewoc J.B., Izworski A. and Skowronski S., Alsis Case Study Computer Integrated Manufacturing and Management Systems. In.: Applications of Large Scale Industrial Systems (IFAC), Helsinki-Stockholm, 2006.

16. Lewoc J.B., Izworski A., Skowronski S. and Kieleczawa A., Some Problems with Technology Transfer in Lower Silesia. In: DECOM 2007 (IFAC), Cesme, 2007.

17. Izworski A., Lewoc J.B. and Piwowar B., Some Aspects of Technology Transfer - A Case Study, In: SWISS '01, Vienna, 2001.

18. Lewoc J.B., A Case Study: Practical Ethical Aspects for Technology Transfer and Change in Computer Control System Development. In; IFAC Congress, Prague, 2005.

19. Lewoc J.B., Izworski A. and Skowronski S., Economic, Ethical and Cultural Aspects of ICT Change in Power System Automation: a Case Study of Poland. In: ISA (IFAC), Prishtina, 2006b.

20. Wikipedia, QNX. Available at http://en.wikipedia.org/wiki/QNX, 2007.

21. J.B. Lewoc, Izworski A. and Skowronski S.. Performance Modelling of a Computer Integrated Manufacturing and Management System. Eurosim Congress, Ljubljana, 2007. 